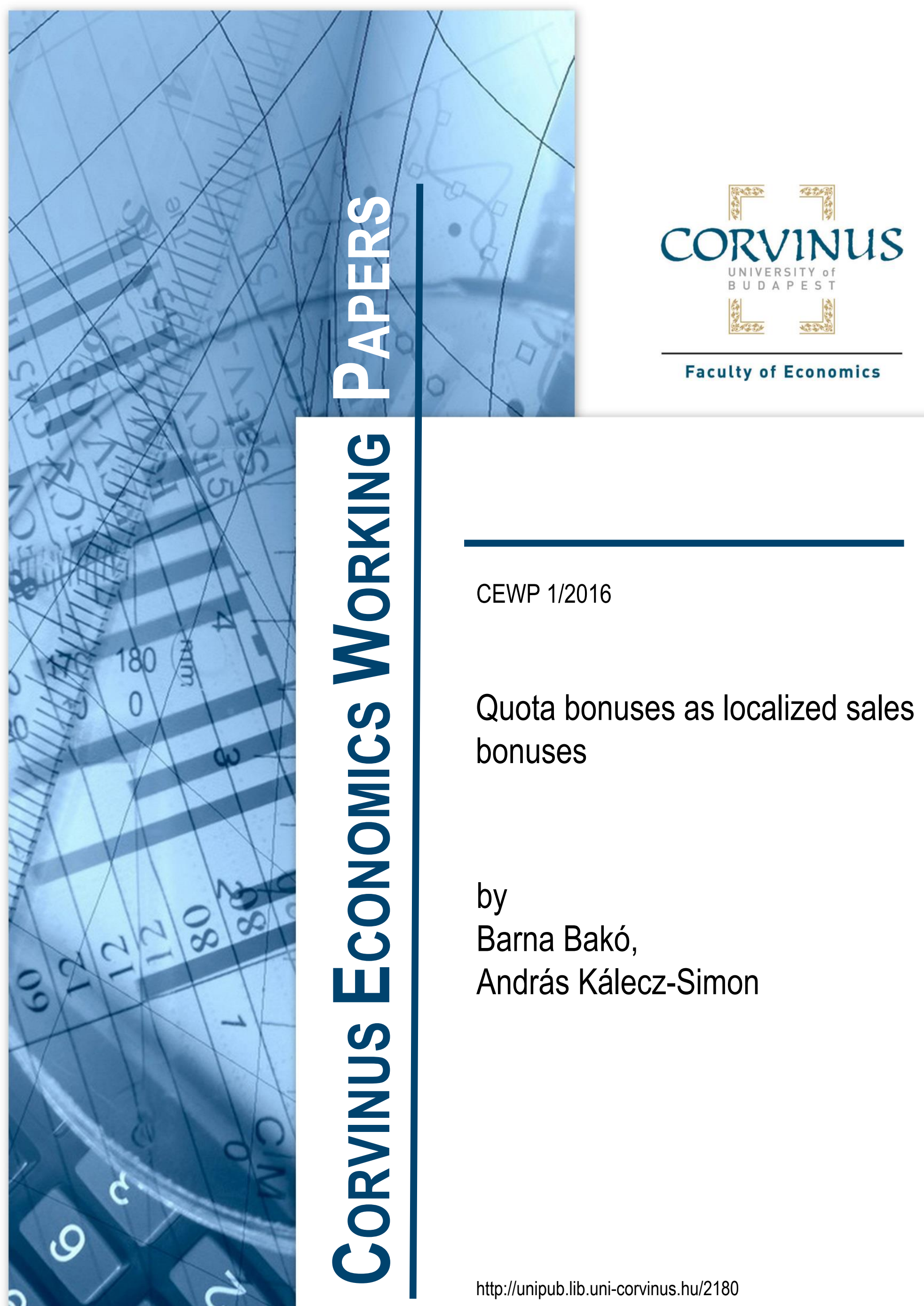




\title{
Quota bonuses as localized sales bonuses
}

\author{
Barna Bakó* András Kálecz-Simon ${ }^{\dagger}$
}

December 23, 2015

\begin{abstract}
Managerial bonus schemes and their effects on firm strategies and market outcomes are extensively discussed in the literature. Though quota bonuses are not uncommon in practice, they have not been analysed so far. In this article we compare quota bonuses to profit-based evaluation and sales (quantity) bonuses. In a duopoly setting with independent demand shocks we find that under certain circumstances choosing quota bonuses is a dominant strategy. This may explain the widespread use of quota bonuses in situations where incentive problems are relevant.
\end{abstract}

\section{Introduction}

One of the most often used assumption of economic theory is that the goal of the firm is profit-maximization. However, as Vickers (1985) indicates while the separation of ownership and management leads to richer strategic opportunities the incentives of the owner and the manager may not be compatible with each other. When the objective of the owner and the manager is different, intended profit-maximization might not lead to actual profit-maximization. To overcome this problem owners often choose bonus systems to align incentives.

The existing literature on managerial bonuses and compensation, following Fershtman and Judd (1987) and Sklivas (1987) besides Vickers (1985) focuses mainly on compensation schemes that are linear in some observable measure (e.g. profits, revenue, relative profits, market share) linked to managerial decisions. ${ }^{1}$ Yet, non-linear bonuses, such as the sales quota, when the agent receives a lump-sum bonus if sales exceed a prescribed target, are often used in corporate practice. For example, according to the empirical study of Joseph and Kalwani (1998), only 5 percent of the companies participating in the survey paid a fixed salary for their salespersons and 24 percent of them paid a commission over the

*MTA-BCE 'Lendúlet' Strategic Interactions Research Group, Corvinus University of Budapest, Department of Microeconomics, Fővám tér 8, E225-A, Budapest, 1093, Hungary, e-mail: barna.bako@uni-corvinus.hu

${ }^{\dagger}$ Corvinus University of Budapest, Department of Macroeconomics, Fővám tér 8, E225-A, Budapest, 1093, Hungary, e-mail: revelation.principle@gmail.com

${ }^{1}$ For more details see Miller and Pazgal (2002) and Jansen et al. (2007). 
fixed salary, whilst the majority of the companies offered a compensation package to the salespersons which included the possibility of some kind of bonus. The firms answering the survey indicated the comparison of actual sales and predetermined quotas as the most important factor influencing bonuses. Furthermore, Murphy (2001) points out it is not uncommon for managers either to receive some kind of lump-sum bonus if they achieve a certain target. Similarly, Oyer (1998) remarks that contracts of top managers often include quota-like clauses. The author also claims that a potential dynamic problem might arise in this situation, since agents may exert higher effort when the date of bonus determination is close, which can lead to uneven level of effort during the bonus period. Thus top managers or salespersons can behave in an opportunistic way when facing a quota-like compensation scheme. They can participate in "timing games", i.e. they can speed up the signing of contracts or use creative accounting methods to ensure they obtain the bonus for fulfilling the quota. However, the results of the analysis of individual level sales data by Steenburgh (2008) seems to indicate that such "timing games" rarely if ever happen, and the main effect of applying quotas is an increase in the salespersons' efforts.

The above results already hint at the fact that quotas influence the decisionmaker in a peculiar way. Healy (1985) emphasises that when the bonus system includes an upper limit, managers have lower incentives to report revenue above this limit. Leventis (1997) analyzed the behavior of New York surgeons, finding that when they approach the penalty limit for malpractice, they are more prone to choose low-risk procedures. Among Navy recruiters Asch (1990) found that their efforts increased before the date of evaluations, and decreased following that.

In spite of their practical relevance, to our knowledge quotas are not yet formally analyzed in the literature of managerial bonuses. ${ }^{2}$ In this article we present a formal model of quota bonuses compatible with the previous empirical findings. We analyze the problem of quota bonuses in an oligopoly setting with demand shocks. The model intends to grasp the 'locality' of quotas as seen in the above empirical examples: the closer an agent is to the prescribed quota, the stronger its influence is going to be on their behavior. Our results indicate that choosing quota bonuses can indeed be a dominant strategy.

\section{The model}

The model builds on a Cournot duopoly. ${ }^{3}$ The owners of both firms aim to maximize their respective profits, while the managers making the operative decisions aim to maximize their respective incomes. For the sake of simplicity, we assume that firms have no costs.

Products are homogeneous and following Jansen et al. (2007) we assume the

\footnotetext{
${ }^{2}$ Non-linear compensation systems are hardly ever discussed in the literature. For a very specific discussion on piecewise-linear incentive systems see Chen and Miller (2009).

${ }^{3}$ The differences between Cournot and Bertrand competition regarding managerial bonuses is discussed in Sklivas (1987) and Jansen et al. (2007).
} 
normalized inverse demand function to be $P=1-Q$, where $P$ is the price and $Q$ is the industry output. We further assume that there is some uncertainty about the sales that take place within a given period. This could be due to unintended timing problems, such as delays in contracting or orders arriving in the last minute. This quantity shock is from normal distribution with a mean of 0 and a variance of $\sigma^{2}$. The firms' respective shocks are independent. Therefore if the manager of firm $i$ decides to sell $q_{i}$ units, and that of firm $j$ decides to sell $q_{j}$ units, then the actual sales within the period are $q_{i}+\varepsilon_{i}$ and $q_{j}+\varepsilon_{j}$ respectively, where $\varepsilon_{i} \sim N\left(0, \sigma^{2}\right), \varepsilon_{j} \sim N\left(0, \sigma^{2}\right)$ and $\operatorname{Cov}\left(\varepsilon_{i}, \varepsilon_{j}\right)=0$.

We assume that the owners, as well as the managers, are risk neutral. ${ }^{4}$ In section 4 we discuss the possible implications of alternate attitudes to risk.

We posit three possible compensation schemes.

i) Evaluation based exclusively on profit: in this case the variable part of the manager's income is proportional to the profit of the firm: $r \pi_{i}$, where $r$ is the profit share of the manager. According to this, the manager of firm $i$ maximizes the following expression:

$$
E\left[\left(1-\left(q_{i}+\varepsilon_{i}\right)-\left(q_{j}+\varepsilon_{j}\right)\right)\left(q_{i}+\varepsilon_{i}\right)\right]=\left(1-q_{i}-q_{j}\right) q_{i}-\sigma^{2}
$$

ii) Sales bonus: in this case the variable part of the manager's income depends on the profit of the firm, but also on the quantity sold: $r_{i} \pi_{i}+b_{i} q_{i}$, where $q_{i}$ is the amount sold by firm $i$ and $b_{i}$ is the per unit sales bonus offered by firm $i$. Thus the manager of firm $i$ maximizes the following expression:

$$
E\left[\left(1-\left(q_{i}+\varepsilon_{i}\right)-\left(q_{j}+\varepsilon_{j}\right)\right)\left(q_{i}+\varepsilon_{i}\right)+\lambda_{i}\left(q_{i}+\varepsilon_{i}\right)\right]=\left(1-q_{i}-q_{j}\right) q_{i}-\sigma^{2}+\lambda_{i} q_{i},
$$

where $\lambda_{i} \equiv \frac{b}{r_{i}}$ is a coefficent of the bonus scheme (more precisely it is the ratio of the per unit sales bonus and the profit share of the manager) determined by the owner of firm $i$.

iii) Quota bonus: in this case the variable part of the manager's income depends on the profit of the firm, but the manager also receives a fixed amount if the sales quota is met: $r_{i} \pi_{i}+Q_{i}$, if $q_{i} \geq \bar{q}$ and $r_{i} \pi_{i}$ otherwise, where $\bar{q}$ is the sales quota set by the owner. Accordingly, the manager maximizes:

$$
\begin{array}{r}
E\left[\left(1-\left(q_{i}+\varepsilon_{i}\right)-\left(q_{j}+\varepsilon_{j}\right)\right)\left(q_{i}+\varepsilon_{i}\right)+\lambda_{i} P\left[\left(q_{i}+\varepsilon_{i}\right) \geq \bar{q}\right)\right]= \\
=\left(1-q_{i}-q_{j}\right) q_{i}-\sigma^{2}+\lambda\left(\frac{1}{2}+\frac{1}{\sqrt{\pi}} \int_{0}^{\frac{q_{i}-\bar{q}}{\sigma \sqrt{2}}} \mathrm{e}^{-t^{2}} \mathrm{~d} t\right),
\end{array}
$$

where $\lambda_{i} \equiv \frac{Q_{i}}{r_{i}}$ is a bonus coefficient determined by the owner of firm $i$, furthermore $\stackrel{r_{i}}{P}\left[\left(q_{i}+\varepsilon_{i}\right) \geq \bar{q}\right]$ is the probability that actual sales meet or exceed the quota, given that the manager planned to sell $q_{i}$ units.

\footnotetext{
${ }^{4}$ Similarly to Fershtman and Judd (1987).
} 
We assume - in line with the previous literature - that the owners maximize their gross profit, i.e. their profit before paying managerial compensation. On the other hand we assume that if two methods lead to the same level of gross profit, the owner will prefer the one with lower cost of compensation. These assumptions asymptotically lead to the same result as actual profit maximization, if the magnitude of compensation payments is significantly smaller than that of the firm's profit.

We posit the following game. In period 0 the owners announce the profit share $r_{i}$ and hire the manager. ${ }^{5}$ In period 1 - if necessary - owners choose the amount and conditions of the bonus. In period 2 managers choose the planned output of their firms, shocks are realized, actual outputs are determined and the market clears.

\section{Results}

\subsection{Cases without quotas}

The following results are well-known. We present them in order to compare them to later results.

Lemma 1. If both owners base their evaluation exclusively on profit, a classical Cournot duopoly is formed in the 2 period, thus the expected outputs and profits are respectively

$$
q_{1}=q_{2}=\frac{1}{3}
$$

and

$$
\pi_{1}=\pi_{2}=\frac{1}{9}
$$

Lemma 2. If the owner of firm 1 bases their evaluation exclusively based on profit, while the owner of firm 2 introduces a sales bonus, then in period 2 we get an outcome equivalent to a Stackelberg duopoly ${ }^{6}$. The respective outputs, profits and bonuses are

$$
q_{1}=\frac{1}{4}, \quad q_{2}=\frac{1}{2}
$$

and

$$
\pi_{1}=\frac{1}{16}, \quad \pi_{2}=\frac{1}{8}
$$

\footnotetext{
${ }^{5}$ Notice that because of uncertainty and symmetry in equilibrium all firms offer the same profit share.

${ }^{6}$ Similarly to the result of Basu (1995).
} 
while

$$
\lambda_{2}=\frac{1}{4}
$$

Lemma 3. If both owners introduces a sales bonus, then the respective outputs, profits and bonus coefficients are ${ }^{7}$

$$
\begin{gathered}
q_{1}=q_{2}=\frac{2}{5} \\
\pi_{1}=\pi_{2}=\frac{2}{25}
\end{gathered}
$$

and

$$
\lambda_{1}=\lambda_{2}=\frac{1}{5}
$$

\subsection{Exclusively profit-based evaluation versus quota bonus}

Let us consider the case when the owner of firm 1 bases their evaluation exclusively on profit while the owner of firm 2 pays quota bonus.

Since the owner of firm 1 does not make any strategic decisions in period 1 , we can presume that similarly to the case of sales bonus ${ }^{8}$, the owner of firm 2 can set such incentives in period 1 that commit the manager to produce the Stackelberg leader output.

If the manager of firm 1 maximizes the expected profit of the firm, i.e. the following equation ${ }^{9}$

$$
S\left(q_{1}\right)=q_{1}\left(1-q_{1}-q_{2}\right),
$$

then they choose quantities according to the following first-order condition

$$
\frac{\partial S\left(q_{1}\right)}{\partial q_{1}}=1-2 q_{1}-q_{2}=0
$$

The manager of firm 2 maximizes the following expression:

$$
S\left(q_{2}\right)=q_{2}\left(1-q_{1}-q_{2}\right)+\lambda_{2}\left(\frac{1}{2}+\frac{1}{\sqrt{\pi}} \int_{0}^{\frac{q_{2}-\bar{q}}{\sqrt{2} \sigma}} \mathrm{e}^{-t^{2}} \mathrm{~d} t\right)
$$

thus chooses quantities according to the following first-order condition

$$
\frac{\partial S\left(q_{2}\right)}{\partial q_{2}}=1-q_{1}-2 q_{2}+\lambda_{2} \frac{\mathrm{e}^{-\frac{\left(\bar{q}-q_{2}\right)^{2}}{2 \sigma^{2}}}}{\sqrt{2 \pi} \sigma}=0 .
$$

\footnotetext{
${ }^{7}$ See eg. Vickers (1985)

${ }^{8}$ As well as the case of the market share bonus (see Jansen et al. (2007)) or that of the bonus based on relative profit (see Miller and Pazgal (2002)).

${ }^{9}$ Hereafter we leave out the terms including the variance, since they do not affect the first-order conditions.
} 
If we would solve the system of equations comprising equations (5) and (7), we could obtain the expected outputs and then calculate the expected profits. This is, however, not a trivial task. Thus we will first assume the incentives applied by the owner of firm 2 and then check whether they were optimal.

It can be easily shown that if the owner of firm 2 introduces the system of incentives below

$$
\begin{aligned}
\bar{q} & =\frac{1}{2} \\
\lambda_{2} & =\frac{\sigma}{2} \sqrt{\frac{\pi}{2}}
\end{aligned}
$$

then the respective outputs are:

$$
q_{1}=\frac{1}{4} \quad \text { and } \quad q_{2}=\frac{1}{2}
$$

Since these are the output levels of a Stackelberg duopoly, we can give the respective profits, which are

$$
\pi_{1}=\frac{1}{16} \quad \text { and } \quad \pi_{2}=\frac{1}{8}
$$

and furthermore we have shown that they are truly optimal.

Proposition 1. If the owner of the other firm evaluates exclusively based on profits, then sales bonus and quota bonus leads to the same outcome. However, since:

$$
\left.q_{s} \cdot \lambda_{s}=\frac{1}{2} \cdot \frac{1}{4}>\frac{1}{2} \cdot \frac{\sigma}{2} \sqrt{\frac{\pi}{2}}=P\left[\left(q_{q}+\varepsilon_{q}\right) \geq \bar{q}\right)\right] \lambda_{q}
$$

in the case of sufficiently low $\sigma s\left(\sigma<\sigma^{*} \approx 0.398942\right)$ the cost of quota bonus will be lower.

\subsection{Sales bonus versus quota bonus}

Let us investigate the case when the owner of firm 1 introduces a sales bonus, while that of firm 2 introduces a quota bonus.

The manager of firm 1 maximizes the following function

$$
S\left(q_{1}\right)=q_{1}\left(1-q_{1}-q_{2}\right)+\lambda_{1} q_{1},
$$

thus chooses quantity according to the following first-order condition

$$
\frac{\partial S\left(q_{1}\right)}{\partial q_{1}}=1-2 q_{1}-q_{2}+\lambda_{1}=0 .
$$

The manager of firm 2 maximizes the following expression 


$$
S\left(q_{2}\right)=q_{2}\left(1-q_{1}-q_{2}\right)+\lambda_{2}\left(\frac{1}{2}+\frac{1}{\sqrt{\pi}} \int_{0}^{\frac{q_{2}-\bar{q}}{\sigma \sqrt{2}}} \mathrm{e}^{-t^{2}} \mathrm{~d} t\right)
$$

thus chooses quantity according to the following first-order condition

$$
\frac{\partial S\left(q_{2}\right)}{\partial q_{2}}=1-q_{1}-2 q_{2}+\lambda_{2} \frac{\mathrm{e}^{-\frac{\left(\bar{q}-q_{2}\right)^{2}}{2 \sigma^{2}}}}{\sigma \sqrt{2 \pi}}=0 .
$$

It is easy to see that the best-response function of the manager of firm 2 cannot be expressed in a closed form. However, under certain conditions we can invoke the implicit function theorem.

The theorem can be used if the Jacobi matrix of the partial derivatives is not zero in an environment of the solution, i.e. ${ }^{10}$

$$
|J|=\left|\begin{array}{cc}
\frac{\partial F_{1}}{q_{1}} & \frac{\partial F_{1}}{q_{2}} \\
\frac{\partial F_{2}}{q_{1}} & \frac{\partial F_{2}}{q_{2}}
\end{array}\right|=\left|\begin{array}{cc}
-2 & -1 \\
-1 & -2-\lambda_{2} \frac{\mathrm{e}^{-\frac{\left(q_{2}-\bar{q}\right)^{2}}{2 \sigma^{2}}}}{\sigma \sqrt{2 \pi}} \frac{q_{2}-\bar{q}}{\sigma^{2}}
\end{array}\right| \neq 0
$$

The relevant first-order condition for the owner of firm 1 is

$$
\frac{\partial \Pi_{1}}{\partial \lambda_{1}}=\left(1-2 q_{1}-q_{2}\right) \frac{\partial q_{1}}{\partial \lambda_{1}}-q_{1} \frac{\partial q_{2}}{\partial \lambda_{1}}=0
$$

while for the owner of firm 2 that is

$$
\frac{\partial \Pi_{2}}{\partial \lambda_{2}}=\left(1-q_{1}-2 q_{2}\right) \frac{\partial q_{2}}{\partial \lambda_{2}}-q_{2} \frac{\partial q_{1}}{\partial \lambda_{2}}=0
$$

Assuming that the (16) condition holds, we can find the partial derivatives with the help os the implicit function theorem.

$$
\begin{gathered}
\frac{\partial q_{1}}{\lambda_{1}}=\frac{\left|\begin{array}{cc}
\frac{\partial F_{1}}{\lambda_{1}} & \frac{\partial F_{1}}{q_{2}} \\
\frac{\partial F_{2}}{\lambda_{1}} & \frac{\partial F_{2}}{q_{2}}
\end{array}\right|}{|J|}=\frac{\lambda_{2} \frac{\mathrm{e}^{-\frac{\left(q_{2}-\bar{q}\right)^{2}}{2 \sigma^{2}}}}{\sigma \sqrt{2 \pi}} \frac{q_{2}-\bar{q}}{\sigma^{2}}-2}{|J|} \\
\frac{\partial q_{2}}{\lambda_{1}}=\frac{\left|\begin{array}{ll}
\frac{\partial F_{1}}{q_{1}} & \frac{\partial F_{1}}{\lambda_{1}} \\
\frac{\partial F_{2}}{q_{1}} & \frac{\partial F_{2}}{\lambda_{1}}
\end{array}\right|}{|J|}=\frac{1}{|J|} \\
\frac{\partial q_{1}}{\lambda_{2}}=\frac{\left|\begin{array}{ll}
\frac{\partial F_{1}}{\lambda_{2}} & \frac{\partial F_{1}}{\lambda_{2}} \\
\frac{\partial F_{2}}{q_{2}}
\end{array}\right|}{|J|}=\frac{\frac{e^{-\frac{\left(\bar{q}-q_{2}\right)^{2}}{2 \sigma^{2}}}}{\sigma \sqrt{2 \pi}}}{|J|} \\
\frac{\partial q_{2}}{\lambda_{2}}=\frac{\left|\begin{array}{ll}
\frac{\partial F_{1}}{q_{1}} & \frac{\partial F_{1}}{\lambda_{2}} \\
\frac{\partial F_{2}}{q_{1}} & \frac{\partial F_{2}}{\lambda_{2}}
\end{array}\right|}{|J|}=\frac{-2 \frac{\mathrm{e}^{-\frac{\left(q_{2}-\bar{q}\right)^{2}}{2 \sigma^{2}}}}{\sigma \sqrt{2 \pi}}}{|J|}
\end{gathered}
$$

${ }^{10}$ Hereon we refer to the left hand sides of equations (13) and (15) as $F_{1}$ and $F_{2}$ respectively. 
Substituting the partial derivatives into equations (17) and (18), we get the following equations after simplification

$$
\begin{gathered}
\frac{\partial \Pi_{1}}{\partial \lambda_{1}}=3 q_{1}+2 q_{2}-2+\left(1-2 q_{1}+q_{2}\right) \lambda_{2} \frac{\mathrm{e}^{-\frac{\left(q_{2}-\bar{q}\right)^{2}}{2 \sigma^{2}}}}{\sigma \sqrt{2 \pi}} \frac{\bar{q}-q_{2}}{\sigma^{2}}=0 \\
\frac{\partial \Pi_{2}}{\partial \lambda_{2}}=2 q_{1}+3 q_{2}-2=0
\end{gathered}
$$

Notice, however, that from equation (15):

$$
\lambda_{2} \frac{\mathrm{e}^{-\frac{\left(q_{2}-\bar{q}\right)^{2}}{2 \sigma^{2}}}}{\sigma \sqrt{2 \pi}}=q_{1}+2 q_{2}-1
$$

thus we can express the first-order condition for the owner of firm 1 in the following way

$$
\frac{\partial \Pi_{1}}{\partial \lambda_{1}}=3 q_{1}+2 q_{2}-2+\left(1-2 q_{1}+q_{2}\right)\left(q_{1}+2 q_{2}-1\right) \frac{\bar{q}-q_{2}}{\sigma^{2}}=0
$$

Let $k$ stand for the expression $\frac{\bar{q}-q_{2}}{\sigma^{2}}$ ! The optimal $k$ cannot be negative, since in this case choosing $-k$ would present the same incentives for the manager but the expected cost of the bonus system would be lower.

Let us assume first that $k$ is pozitive! Solving (24) and (26) as a system of equations leads to the following result ${ }^{11}$

$$
\begin{aligned}
& q_{1}=\frac{5 k-3(5-\sqrt{25-(6-k) k})}{8 k} \\
& q_{2}=\frac{5+k-\sqrt{25-(6-k) k}}{4 k}
\end{aligned}
$$

Thus the owner of firm 2 maximizes the expression $\frac{(5+k-\sqrt{25-(6-k) k})^{2}}{32 k^{2}}$. However, the derivative of the above expression is negative for all positive values of $k$, thus the optimal value of $k$ is zero. Hence

$$
q_{1}=q_{2}=\frac{2}{5}
$$

so

$$
\bar{q}=\frac{2}{5}
$$

From this we have that

$$
\lambda_{1}=\frac{1}{5} \quad \text { and } \quad \lambda_{2}=\frac{\sigma}{5} \sqrt{2 \pi}
$$

\footnotetext{
${ }^{11}$ We excluded potential solutions of the system of equations that would lead to negative output and/or negative bonus.
} 
Proposition 2. If the other firm introduces a sales bonus, then a sales bonus or a quota bonus leads to the same outcome. However, since

$$
\left.q_{s} \cdot \lambda_{s}=\frac{2}{5} \cdot \frac{1}{5}=\frac{2}{25}>\frac{1}{2} \cdot \frac{\sigma}{5} \sqrt{2 \pi}=P\left[\left(q_{q}+\varepsilon_{q}\right) \geq \bar{q}\right)\right] \cdot \lambda_{q}
$$

if $\sigma$ is sufficiently low ( $\left.\sigma<\sigma^{*} \approx 0.319154\right)$, the expected cost of the quota bonus is lower for the owner of firm 2 .

\subsection{Both firms use quota bonus}

Finally we discuss the case when both owners introduces a quota bonus.

The manager of firm 1 maximizes the expression below

$$
S\left(q_{1}\right)=q_{1}\left(1-q_{1}-q_{2}\right)+\lambda_{1}\left(\frac{1}{2}+\frac{1}{\sqrt{\pi}} \int_{0}^{\frac{q_{1}-\bar{q}_{1}}{\sigma \sqrt{2}}} \mathrm{e}^{-t^{2}} \mathrm{~d} t\right)
$$

thus chooses quantity according to the following first-order condition

$$
\frac{\partial S\left(q_{1}\right)}{\partial q_{1}}=1-2 q_{1}-q_{2}+\lambda_{1} \frac{\mathrm{e}^{-\frac{\left(\bar{q}_{1}-q_{1}\right)^{2}}{2 \sigma^{2}}}}{\sigma \sqrt{2 \pi}}=0 .
$$

The manager of firm 2 maximizes the following expression

$$
S\left(q_{2}\right)=q_{2}\left(1-q_{1}-q_{2}\right)+\lambda_{2}\left(\frac{1}{2}+\frac{1}{\sqrt{\pi}} \int_{0}^{\frac{q_{2}-\bar{q}_{2}}{\sigma \sqrt{2}}} \mathrm{e}^{-t^{2}} \mathrm{~d} t\right)
$$

thus chooses quantity according to the following first-order condition

$$
\frac{\partial S\left(q_{2}\right)}{\partial q_{2}}=1-q_{1}-2 q_{2}+\lambda_{2} \frac{\mathrm{e}^{-\frac{\left(\bar{q}_{2}-q_{2}\right)^{2}}{2 \sigma^{2}}}}{\sigma \sqrt{2 \pi}}=0 .
$$

Applying the implicit function theorem we get the following ${ }^{12}$

$$
\begin{gathered}
\frac{\partial q_{1}}{\lambda_{1}}=\frac{\mathrm{e}^{-\frac{\left(\bar{q}_{1}-q_{1}\right)^{2}+\left(\bar{q}_{2}-q_{2}\right)^{2}}{2 \sigma^{2}}}\left(\lambda_{2}\left(\bar{q}_{2}-q_{2}\right)-2 \mathrm{e}^{\frac{\left(\overline{\left.q_{2}-q_{2}\right)^{2}}\right.}{2 \sigma^{2}}} \sqrt{2 \pi} \sigma^{3}\right)}{2 \pi \sigma^{4}} \\
\frac{\partial q_{2}}{\lambda_{1}}=\frac{\mathrm{e}^{-\frac{\left(\bar{q}_{1}-q_{1}\right)^{2}}{2 \sigma^{2}}}}{\sigma \sqrt{2 \pi}} \\
\frac{\partial q_{1}}{\lambda_{2}}=\frac{\mathrm{e}^{-\frac{\left(\bar{q}_{2}-q_{2}\right)^{2}}{2 \sigma^{2}}}}{\sigma \sqrt{2 \pi}} \\
\frac{\partial q_{2}}{\lambda_{2}}=\frac{\mathrm{e}^{-\frac{\left(\bar{q}_{2}-q_{2}\right)^{2}+\left(\bar{q}_{1}-q_{1}\right)^{2}}{2 \sigma^{2}}}\left(\lambda_{1}\left(\bar{q}_{1}-q_{1}\right)-2 \mathrm{e}^{\frac{\left(\bar{q}_{1}-q_{1}\right)^{2}}{2 \sigma^{2}}} \sqrt{2 \pi} \sigma^{3}\right)}{2 \pi \sigma^{4}}
\end{gathered}
$$

\footnotetext{
${ }^{12}$ For simplicity, we do not use the actual value of the partial derivatives, but we multiply them by $|J|$
} 
Using the partial derivatives we get to the following first-order conditions after some simplification

$$
\begin{aligned}
& \frac{\partial \Pi_{1}}{\partial \lambda_{1}}=\lambda_{2}\left(2 q_{1}+q_{2}-1\right)\left(q_{2}-\bar{q}_{2}\right)+\mathrm{e}^{\frac{\left(\bar{q}_{2}-q_{2}\right)^{2}}{2 \sigma^{2}}} \sqrt{2 \pi}\left(3 q_{1}+2 q_{2}-2\right) \sigma^{3}=0 \\
& \frac{\partial \Pi_{2}}{\partial \lambda_{2}}=\lambda_{1}\left(2 q_{2}+q_{1}-1\right)\left(q_{1}-\bar{q}_{1}\right)+\mathrm{e}^{\frac{\left(\bar{q}_{1}-q_{1}\right)^{2}}{2 \sigma^{2}}} \sqrt{2 \pi}\left(3 q_{2}+2 q_{1}-2\right) \sigma^{3}=0
\end{aligned}
$$

In the next step we can obtain from equations (33) and (35) that

$$
\begin{aligned}
& \lambda_{1}=\sqrt{2 \pi} \sigma\left(2 q_{1}+q_{2}-1\right) \mathrm{e}^{\frac{\left(\bar{q}_{1}-q_{1}\right)^{2}}{2 \sigma^{2}}} \\
& \lambda_{2}=\sqrt{2 \pi} \sigma\left(q_{1}+2 q_{2}-1\right) \mathrm{e}^{\frac{\left(\bar{q}_{2}-q_{2}\right)^{2}}{2 \sigma^{2}}}
\end{aligned}
$$

Using these equations we can rewrite the first-order conditions as

$$
\begin{aligned}
& \frac{\partial \Pi_{1}}{\partial \lambda_{1}}=\left(1-q_{1}-2 q_{2}\right)\left(2 q_{1}+q_{2}-1\right) \frac{\bar{q}_{2}-q_{2}}{\sigma^{2}}+\left(3 q_{1}+2 q_{2}-2\right)=0 \\
& \frac{\partial \Pi_{2}}{\partial \lambda_{2}}=\left(1-2 q_{1}-q_{2}\right)\left(2 q_{2}+q_{1}-1\right) \frac{\bar{q}_{1}-q_{1}}{\sigma^{2}}+\left(3 q_{2}+2 q_{1}-2\right)=0
\end{aligned}
$$

Let us denote the expression $\frac{\bar{q}_{1}-q_{1}}{\sigma^{2}}$ by $k_{1}$, and the expression $\frac{\bar{q}_{2}-q_{2}}{\sigma^{2}}$ by $k_{2}$. Notice first that if firm $i(i=1,2)$ chooses zero for $k_{i}$, than we get back to the first-order conditions of the case discussed in section 3.3 , and the best response of the other firm is to choose zero for $k_{-i}$. Limiting the set of possible solutions to symmetric strategy profiles, it is easy to see that if both firms would choose a positive value for $k$, than the respective outputs would exceed $\frac{2}{5}$, thus the strategy profile where $k_{1}=k_{2}=0$ is payoff-dominant.

Thus

$$
\begin{aligned}
& q_{1}=q_{2}=\frac{2}{5} \\
& \bar{q}_{1}=\bar{q}_{2}=\frac{2}{5}
\end{aligned}
$$

and

$$
\lambda_{1}=\lambda_{2}=\frac{\sigma}{5} \sqrt{2 \pi}
$$

From this we can state the following:

Proposition 3. If the other firm introduces a quota bonus, than the sales bonus and the quota bonus leads to the same outcome. However, since

$$
\left.q_{s} \cdot \lambda_{s}=\frac{2}{5} \cdot \frac{1}{5}=\frac{2}{25}>\frac{1}{2} \cdot \frac{\sigma}{5} \sqrt{2 \pi}=P\left[\left(q_{q}+\varepsilon_{q}\right) \geq \bar{q}\right)\right] \cdot \lambda_{q}
$$

if $\sigma$ is sufficiently low $\left(\sigma<\sigma^{*} \approx 0.319154\right)$, the expected cost of the quota bonus is lower for the owner of firm 2. 


\section{Conclusion}

We have seen that the quota bonus leads to the same outcomes as the sales bonus, however, its expected cost is lower. We can draw the conclusion that assuming risk-neutral actors quota bonus is preferred to sales bonus. This, however, might not hold for all risk attitudes. The role of risk tolerance was also emphasized by Ross (1991) who claims that the behavior of agents influences the process of quota determination. In fact, quotas under uncertainty can be seen as gambles. The very same incentives could have different effects on agents with different risk attitudes. Thus in the case of risk-averse actors the cost advantages of the quota bonus indicated by our model can diminish or vanish. This can explain the fact that some firms use sales bonuses, while other firms use quota bonuses. Firms with less risk-averse actors use quota bonuses, while firms with more risk-averse actors offer quota bonuses.

\section{References}

Asch, B. (1990), Do incentives matter? The case of Navy recruiters, Industrial \& Labor Relations Review, 43(3), 89-106.

Basu, K. (1995), Stackelberg equilibrium in oligopoly: an explanation based on managerial incentives, Economics Letters, 49(4), 459-464.

Chen, J. Y. and Miller, B. L. (2009), 'On the relative performance of linear vs. piecewise-linear-threshold inter temporal incentives', Management Science, 55(10), 1743-1752.

Fershtman, C. and Judd, K. L. (1987). Equilibrium incentives in oligopoly, American Economic Review, 77(5), 927-940.

Healy, P. (1985), The effect of bonus schemes on accounting decisions, Journal of Accounting \& Economics, 7, 85-107.

Jansen, T., van Lier, A. and van Witteloostuijn, A. (2007), A note on strategic delegation: the market share case, International Journal of Industrial Organization, 25(3), 531-539,

Joseph, K. and Kalwani, Manohar U. (1998), The role of bonus pay in salesforce compensation plans, Industrial Marketing Management, 27(2), 147-159.

Leventis, A. V. (1997), Cardiac Surgeons Under Scrutiny: A Testable Patientselection Model, Center for Economic Policy Studies, Working Paper 4., Princeton University

Miller, N and Pazgal, A. (2002), Relative performance as a strategic commitment mechanism, Managerial and Decision Economics, 23(2), 51-68.

Murphy, K. J.(2001), Performance standards in incentive contracts, Journal of Accounting \& Economics, 30, 245-278. 
Oyer, Paul (1998), Fiscal year ends and nonlinear incentive contracts: the effect on business seasonality, The Quarterly Journal of Economics, 113(1), 149-185.

Ross, William T. Jr. (1991), Performance against quota and the call selection decision, Journal of Marketing Research, 28(3), 296-306.

Sklivas, Steven D. (1987), The strategic choice of managerial incentives, RAND Journal of Economics, 18(3), 452-458.

Steenburgh, Thomas (2008), Effort or timing: The effect of lump-sum bonuses, Quantitative Marketing and Economics, 6(3), 235-256.

Vickers, John (1985), Delegation and the theory of the firm, Economic Journal, 95(380a), 138-147. 